\title{
Analysis of urban elements orientations to characterize the spatial extension of the foundation of the Roman city of Amida
}

\author{
Jean-François Girres $^{\mathrm{a}, *}$, Martine Assenat ${ }^{\text {,c }}$, Veysel Malıt ${ }^{\mathrm{d}}$ \\ ${ }^{a}$ Univ. Paul-Valéry Montpellier 3, ESPACE-DEV / AMIS, Montpellier,France-jean-francois.girres@univ-montp3.fr \\ ${ }^{b}$ Univ.Paul-Valéry Montpellier 3, CRISES, Montpellier,France-martine.assenat@univ-montp3.fr \\ ' Institut Français d'Etudes Anatoliennes (IFEA), Istanbul, Turkey \\ ${ }^{d}$ Univ. of Harran, Institut of Social Sciences, Department of Geography, Şanliurfa, Turkey-malitveysel@gmail.com \\ * Corresponding author
}

\begin{abstract}
:
The structure of the historical center of the city of Diyarbakır is largely inherited from the Roman city of Amida, through numerous testimonies still present in certain urban elements, such as buildings or cadastral parcels. The detailed analysis of the orientation of these urban elements in the current urban plan of Diyarbakır can contribute in particular to a better understanding of the different eras of foundation of the city of Amida and their spatial extensions. This research proposes to compare two methods of extraction of orientations from urban elements of the city of Diyarbakir. First, historians carried out a manual survey of the orientations from an aerial photograph, which made it possible to bring out two frames corresponding to two eras of the founding of the Roman city of Amida. These orientations were then compared with those extracted automatically from the geographic databases of cadastral parcels and built-up urban elements captured at a large scale. If the results obtained with the two methods converge, they also show differences, both on the orientation values and on the spatial extension of the two frames observed. These differences may contradict the initial observations, but are also sources of new perspectives of research on the spatial extension of the different periods of foundation of the Roman city of Amida. Finally, the results of this research tend to show that the two approaches prove to be complementary in detecting ancient urban structures in a contemporary city plan.
\end{abstract}

Keywords: spatial analysis, orientations, urban patterns, ancient city, Amida

\section{Introduction}

Some contemporary cities owe a significant part of their urban frames to structures inherited from Greek or Roman antiquity. Imposed by a powerful state (or by the authority of a city-state), these ancient cities organized the distribution of urban space in order to institute, by materializing them, geometric norms guaranteeing political and civic laws. Thus, the harmony of society depended, for an essential part, by the will of the gods, the virtue of numbers, and the sustainability of these structures. Whether the foundation of these cities was carried out ex-nihilo or whether it took place on an older site, these plans often wiped out previous plots, or incorporated certain older orientations, thus renewing the symbolic significance of their history. It often happened that the city knew several successive plans.

Consequently, the identification of structures inherited from previous plans is a key element of understanding for any study of urban archaeology, when the contemporary city occupies an ancient site.

However, it is not always very easy to map these ancient structures, which have necessarily evolved, notably by determining their orientation, extension and metric. Thus, the use of geographic information systems and the development of spatial analysis methods dedicated to archaeology (Rodier, 2011) can facilitate the extraction of these ancient patterns.

In this context, different methods of spatial analysis are proposed in order to extract the testimonies of previous urban patterns from the plan of a contemporary city. Several methods appear particularly suitable for the analysis of urban structures, such as the following methods. First, the extraction of indicators of the size and shape of urban blocks can reveal urban structures characteristic of certain periods of the founding of the city (for example, the surfaces of urban blocks verifying the use of ancient units of measurement). Also, the 
analysis of the orientation of the elements constituting an urban frame allow us to bring to light significant evidence of previous occupation. For example, ancient Roman cities could be structured around two main axes: the Cardo (North-South axis) and the Decumanus (East-West axis). Finally, the analysis of the spacing between constituent elements of an urban frame (also called spatial periodicity analysis) offers potential evidence of earlier periods of foundation of the city. This can for example be illustrated by the recurrence of distances between urban elements corresponding to old units of measurement, such as Roman feet (Girres et al. 2018). In this article, we will focus on the analysis of the orientation of the constituent elements of urban frames, in order to determine how the orientation allows to bring out evidences of the past periods of foundation of a city.

We will therefore propose here to analyze the orientations extracted from urban elements, based on different methods of survey. These surveys, which have long been carried out by hand, can also be automated using spatial analysis techniques. The two processes, which may prove to be complementary, also raise methodological questions. This article therefore seeks to compare the orientations of urban elements extracted manually by historians and archaeologists, with those automatically extracted from parcels and buildings using automated spatial analysis techniques.

The example will be applied on the city of Diyarbakır, located in eastern Turkey, which corresponds to the ancient Roman city of Amida. Two ancient patterns have been identified in its urban frame, and will illustrate this study.

\section{Context of the study: Diyarbakir and the Roman city of Amida}

Diyarbakir is a city located in southeastern Turkey, characterized by a large kurdish population. It corresponds to the ancient Roman city of Amida, located by the Tigris river, on the margins of the Roman Empire.

The Roman city of Amida bequeathed to the current city of Diyarbakır an urban plan whose main outlines are remarkably preserved (figure 1). From the four doors of the ancient wall escape:

- the cardines (north-south axis) from the Moutain Gate at the north to the Mardin Gate,

- and the decumani (east-west axis) from the New Gate at the East, to the Urfa Gate at the West.

They intersect in the center of the city, not far from the great mosque, which probably corresponded to the old forum of the city (Assenat and Perez, 2014).

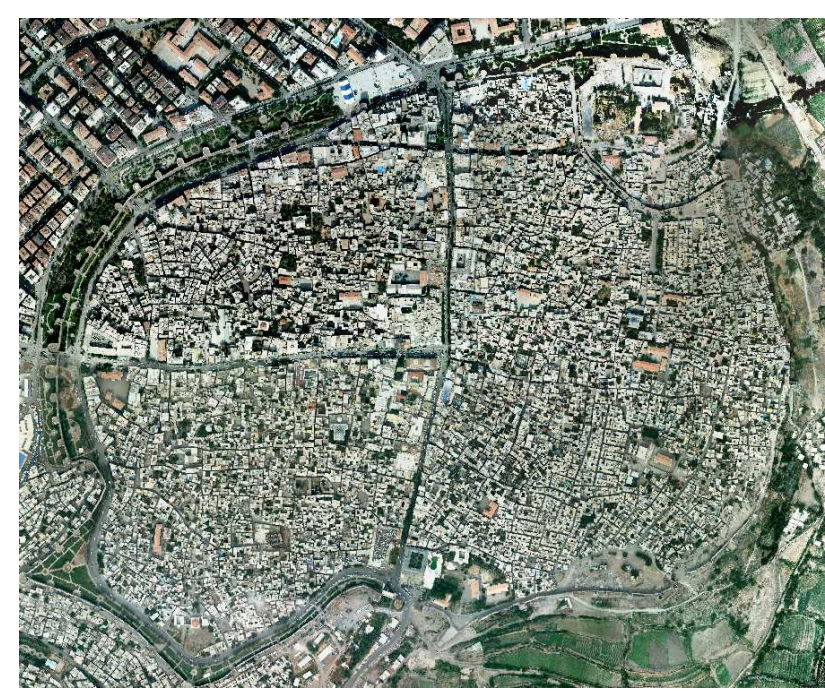

Figure 1. Aerial photography of the historical center of Diyarbakır in 2006.

Such a configuration seems to come directly from an ancient land surveying manual, representing the principles of the ideal city (figure 2).

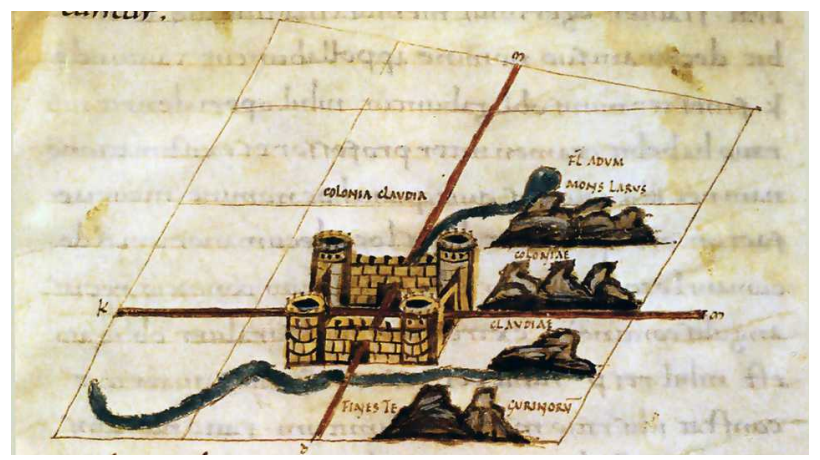

Figure 2. An example of an ideal city: Colonia Claudia, taken from the Palatinus 1564 manuscript (9th century) in Rome, Vatican library no. 90.

The date of the founding of the Roman city of Amida is still debated (Assenat and Perez, 2012). Albert Gabriel is the first to be interested in the topography of Amida and to define the main stages of its foundation (Gabriel, 1940: 175-182). He had already identified the existence of two successive occupations which correspond to two eras of the foundation of the city: a first city, established in the current eastern part of the site, was enlarged towards the West, at a given moment in its history (figure 3).

In his work, Gabriel (1940) only took into account the large masses, which did not allow him to identify more precisely the extension of the different frames. Assenat and Perez (2014) extended this work, seeking to identify with greater precision the spatial extension of the different periods of foundation of the Roman city of Amida. 


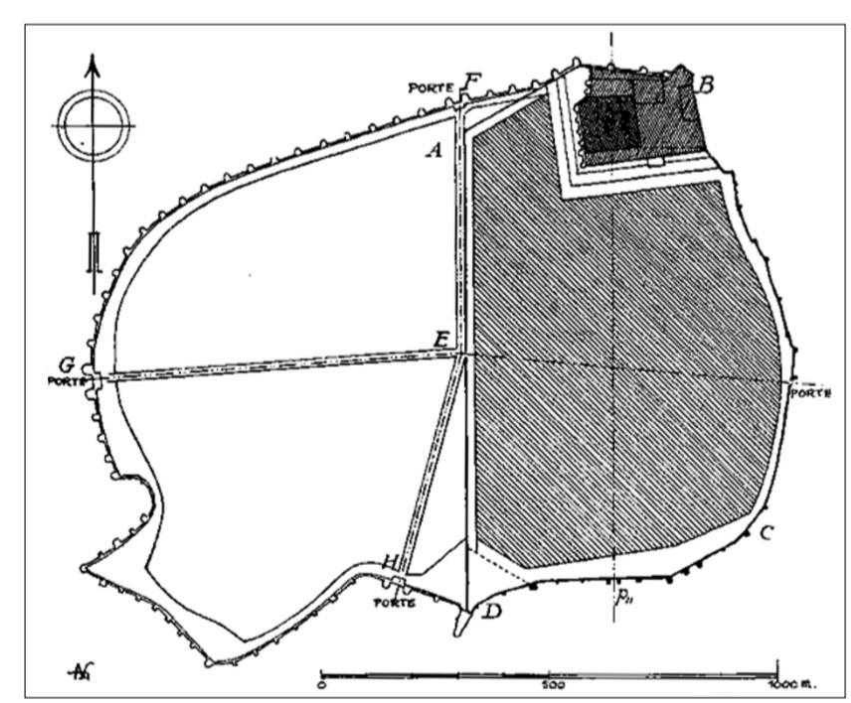

Figure 3. Evolution of the urban plan of Amida according to A. Gabriel, from Assenat and Perez (2014)

From an analysis of the orientation of the constituent elements of the urban frames of Diyarbakir, this study seeks to verify the hypothesis that the Roman city of Amida would be established in two successive periods, and to define the spatial extension of the different frames.

\section{Methodology for measuring the orientation of urban elements}

\section{1. Disaggregation of urban elements}

The definition of the orientation of geographic features can be a difficult task according to the type of geometry used, and the complexity of the assessed objects.

For polylines, the orientation is generally defined by the azimuth between the first and the last vertex. If this simple method does not take into account the internal complexity of the polyline, it allows to determine its main orientation. For polygons, the definition of the orientation is more complex, and many measures have been proposed in the literature. For example, to determine the orientation of a building, the longest side of the polygon, or the orientation of its smallest bounding box can be used (Duchêne et al., 2003).

In this research, we are not trying to determine the orientation of urban elements as a whole, but the orientation of each element that constitutes it, such as each of the walls that compose a building for instance.

As a consequence, each urban element assessed in this research (cadastral parcels, buildings...) is divided into segments, whose orientations are studied separately.

\section{2. Measuring orientations}

To determine the orientation of the segments of urban elements, azimuth measurements are first computed in values between $0^{\circ}$ and $360^{\circ}$ clockwise, where:

- $0^{\circ}$ and $360^{\circ}$ is a segment oriented North,

- $90^{\circ}$ is a segment oriented East,

- $180^{\circ}$ is a segment oriented South,

- $270^{\circ}$ is a segment oriented West.

However, in determining the orientation of a segment, we do not take into account the capture direction of each segment, since this has no meaning in our analysis. For example, a segment oriented $20^{\circ}$ is equivalent to a segment oriented $200^{\circ}$ (Figure $4 \mathrm{a}$ ). To eliminate the capture direction in the analysis of orientations, the orientation values are therefore reduced to values between $0^{\circ}$ and $180^{\circ}$ clockwise, where:

- $0^{\circ}$ and $180^{\circ}$ is a segment oriented North or South,

- $90^{\circ}$ is a segment oriented West or East.

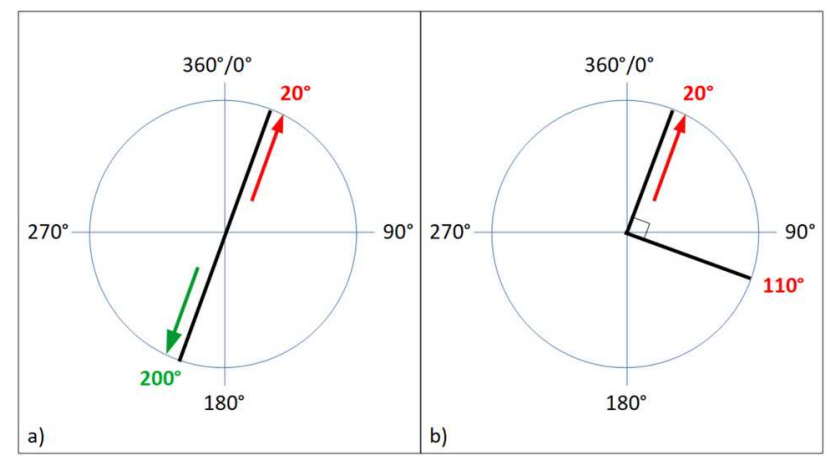

Figure 4. Two orientations $\left(20^{\circ}\right.$ or $\left.200^{\circ}\right)$ of a segment according to its capture direction (a). Two orthogonal segments $\left(20^{\circ}\right.$ and $110^{\circ}$ ) considered characteristics of a same orientation (b).

Finally, the structure of Roman urban cities invites us to take into account the elements orthogonal to a defined orientation. For example, the study of elements oriented North or South cannot be dissociated from orthogonal elements oriented East or West. Thus, the orientation values have also all been reduced between $0^{\circ}$ and $90^{\circ}$ clockwise (see Figure 4b), where:

- $0^{\circ}$ and $90^{\circ}$ is a segment oriented North, South, East, or West,

$-45^{\circ}$ is a segment oriented $45^{\circ}, 135^{\circ}, 225^{\circ}$, or $315^{\circ}$.

The analysis of the orientations extracted from different data sources will therefore be carried out using these three methods, which make it possible to overcome the capture direction of segments, and to study the orthogonal elements in a grouped manner.

The next two sections present the different data and methods used to determine the orientations of the urban elements within the city of Dyarbakir. 


\section{Manual extraction of the orientations of urban elements}

In order to reveal the persistence of two patterns corresponding to two eras of the foundation of the urban city of Amida, a first manual survey of the orientations of the constituent elements of the urban structure of Diyarbakır was carried out by historians specialized in urban archaeology (see Assenat and Perez, 2014, for a detailed proposition of the dating of the urban frames).

This first survey of the isoclinic urban elements of the major axes (ie. the cardo and the decumanus) and the buildings of the great mosque was carried out manually on a printed aerial photography captured in 2006.

Two major orientations were thus identified: an orientation around $0^{\circ}$ (North-South) and an orientation around $10^{\circ}$. However, neither of these two orientations could be measured to the nearest degree, for two reasons. First, it is assumed that certain elements used to determine the orientations have been corrupted by the evolution of the frames over time; and secondly, the human eye is not capable of more acerbic discernment.

Figure 5 results from this manual survey. It illustrates the role of human interpretation (and its underlying subjectivity) in the work of photo-interpretation.

For example, an axis, formerly rectilinear, has ended up adopting an undulating course of which only a few segments retain the original orientation. Yet, the hand of the historian operator who draws somehow reconstructs the lost coherence. Through this accommodation, the connections between groups of urban elements are reconstructed, and the areas where the alignments between urban elements persist are more apparent.

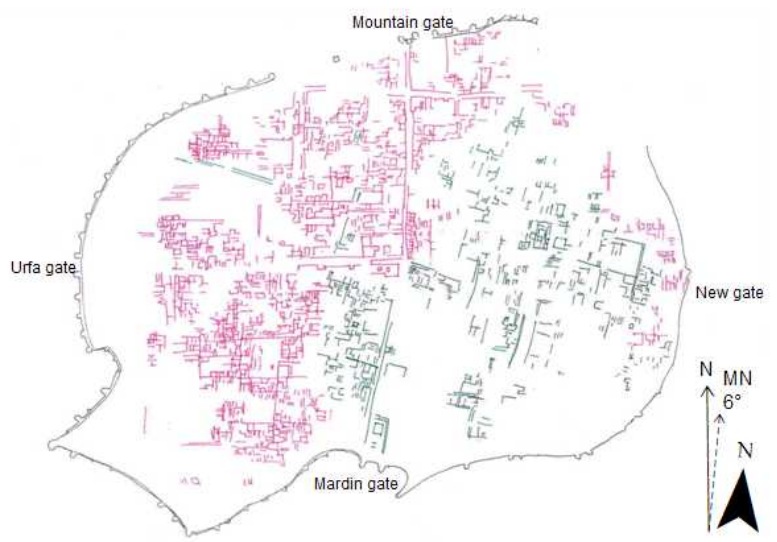

Figure 5. Manual extraction of the two main orientations (green and red) in the Diyarbakir urban structure

Two groups of traces, here green and red, are reproduced on this manual survey.
The green group is present in the eastern part of the city, particularly in the region of the decumanus of the same orientation. It is also found on both sides of the cardo connecting the center to the Mardin door, but it is hardly represented towards the west. It is the red group that occupies the entire western part of the old town where it is much better represented than the green group. Its orientation corresponds to those of the major axis connecting the city center, to the North, to the Mountain door and, to the West, to the Urfa door. In the east side of the city, the red group seems to be enveloping the green group.

Given the part of subjectivity inherent in the work of photo-interpretation, the statements of orientations carried out manually by historians are compared with orientations automatically extracted from the geographic databases of buildings and parcels of the city of Diyarbakır.

\section{Automatic assessment of orientations based on geographical databases}

The observations recorded manually by historians were compared with geographic objects of cadastral parcels and built-up urban elements of the city of Diyarbakır.

The geographic database of parcels was create from a cadastral plan (figure 6), while the database of built-up urban elements was manually captured.

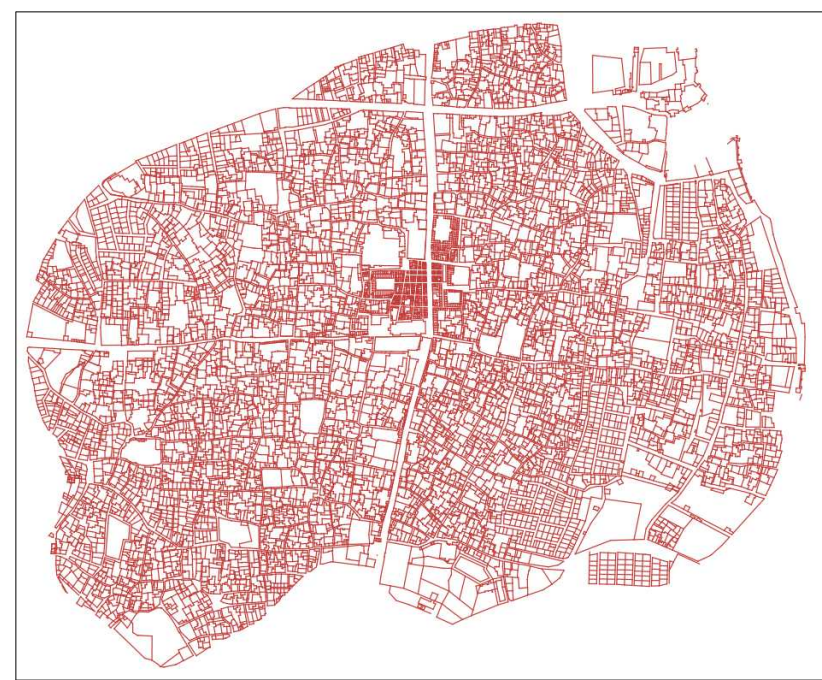

Figure 6. Cadastral parcels of the city of Diyarbakır

To create the database of built-up urban elements, all of the constituent elements of the urban frame were digitized from the 2006 aerial photography. Thus, one by one the limits of streets, avenues, house facades, interior courtyards, squares... were transformed into segments, so that their orientation can be calculated automatically (figure 7). 


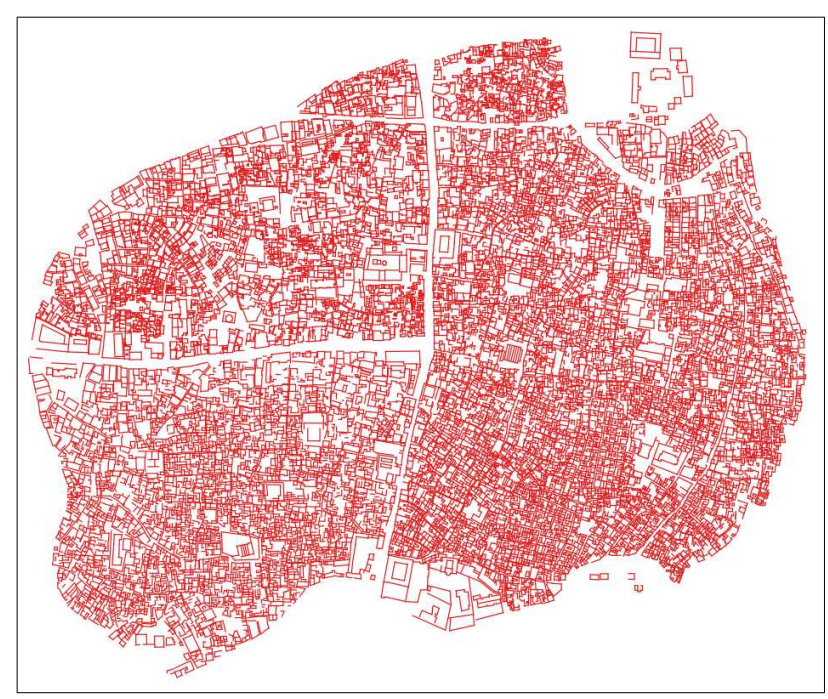

Figure 7. Urban elements of the city of Diyarbakir captured from an aerial photography

From these databases, the green and red groups obtained manually by historians were compared, based on similar orientation values

The automatic restitution of urban elements oriented in a given direction was obtained using an orientation analysis tool, developed as a plugin a the QGIS software (QGIS, 2021). The application thus developed was used to generate cartographic representations making it possible to restore the distribution of urban elements for each degree in a first range around $0^{\circ}$ and in a second around $10^{\circ}$ East. The difference between the automatic and manual surveys is obvious.

Unlike the manual restitution of the orientations, which would tend to reconstruct the continuity of the alignments of elements separated from each other, the automated process has the impact of splitting the alignments of segments to such a point that the orientations would be more difficult to detect without a preliminary manual work. This is particularly observable for the green group, which appears to be more degraded than the red group.

With regard to the red North-South structure (figure 8), we observe that a main orientation at $0^{\circ}$ with a precision of $2-3^{\circ}$, makes it possible to partially restore the elements captured manually in the red group.

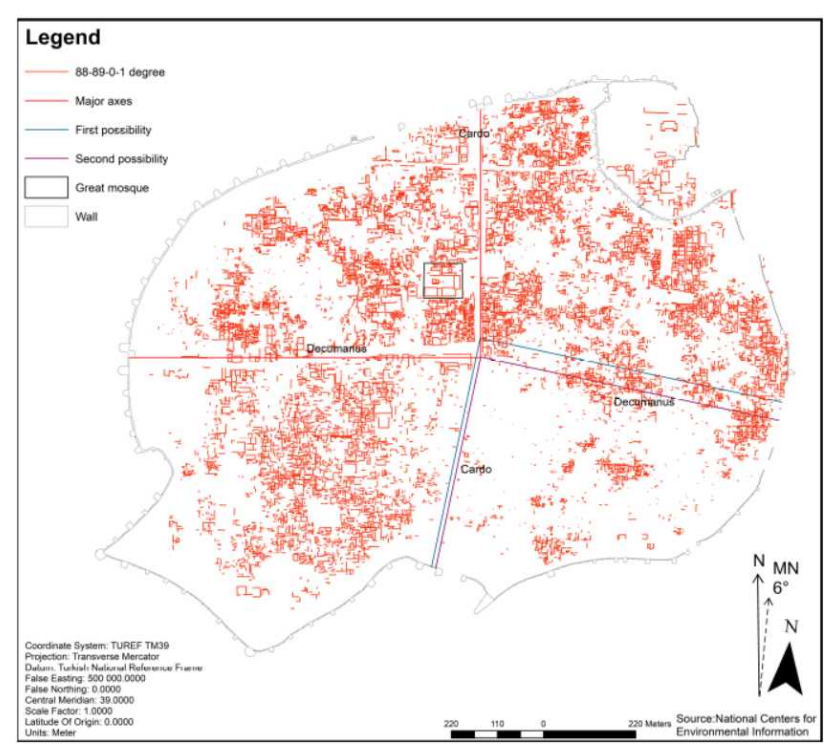

Figure 8. Automatic restitution of urban elements oriented at 0 degree $( \pm 2 / 3$ degrees $)$

Regarding the green structure to the East (figure 9), we observe that the indices decrease from an orientation of $14^{\circ}$. The green group can be rendered in a $9^{\circ}$ orientation, with a precision of $1^{\circ}$.

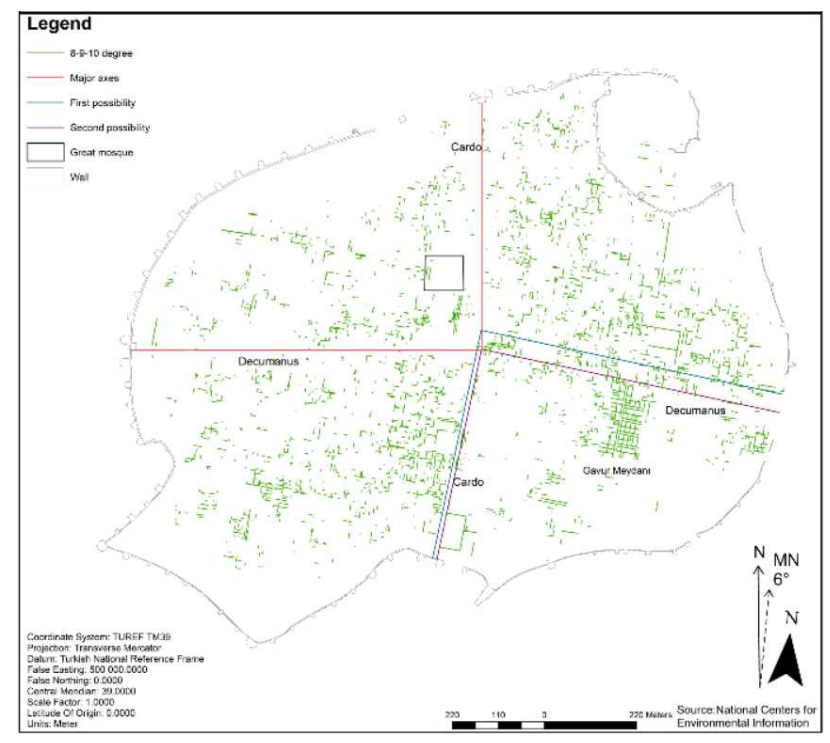

Figure 9. Automatic restitution of urban elements oriented at 9 degrees ( \pm 1 degree)

Beyond the reconstitution of the green and red groups, a more detailed quantitative analysis of the orientations extracted from the cadastral parcels and built-up urban elements is proposed in the following section. 


\section{Analysis of the orientations of urban elements}

In order to quantitatively objectify the observations performed visually, this section presents a detailed analysis of the distributions of orientations of parcels and built-up urban elements in the city of Diyarbakır.

\section{1. Cadastral parcels}

Distribution of orientations of cadastral parcels boundaries is characterized by a majority of North-South and East-West orientations, as shown in figure 10.

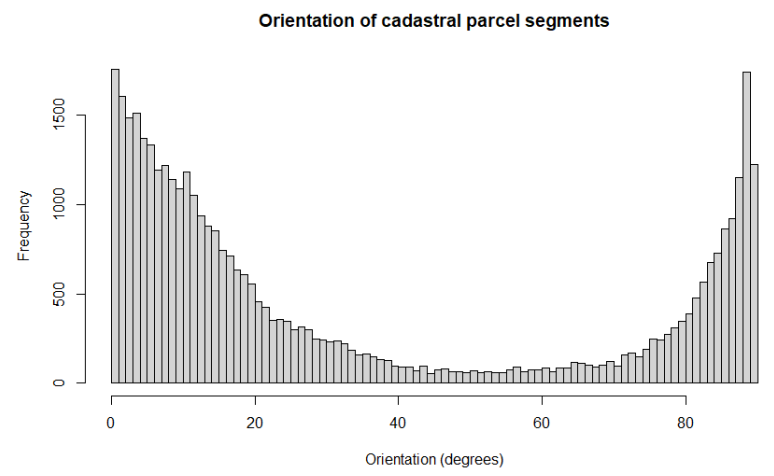

Figure 10. Distribution of the orientations of cadastral parcels boundaries (between $0^{\circ}$ et $90^{\circ}$ ) on the entire city of Diyarbakır

However, by analyzing more precisely this distribution of the orientations, we can observe that the frequency of the orientations between $0^{\circ}$ and $20^{\circ}$ decreases slowly, which tends to indicate that many boundary parcels are oriented in these values. In order to propose a more detailed analysis of the orientations, a study by quadrants is therefore proposed by dividing the cadastral plan of Diyarbakır into four sections, as shown in figure 11.

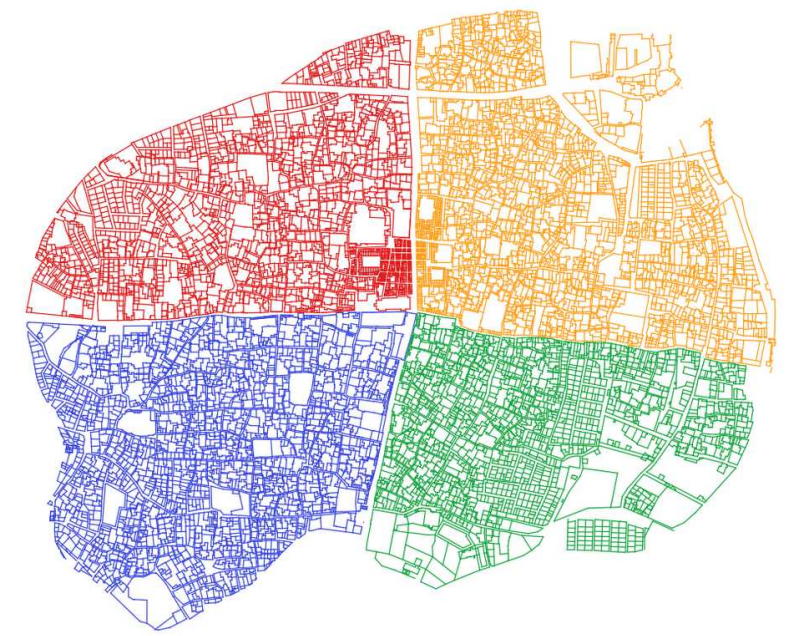

Figure 11. Division of cadastral parcels of the city of Diyarbakir in 4 quadrants

The distribution of the orientations of the cadastral parcels boundaries by quadrant presents very similar results for the North-East, North-West and South-West quadrants with orientations concentrated in North-South and East-West directions (figure 12). These orientations testify to the predominance of the red group in these quadrants.

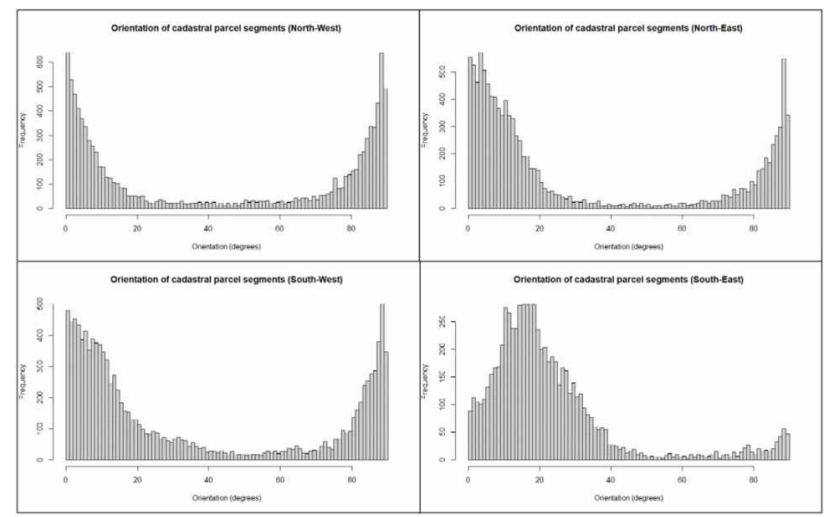

Figure 12. Distribution of the orientations of cadastral parcels boundaries (between $0^{\circ}$ et $90^{\circ}$ ) in each quadrant

Conversely, the South-East quadrant has a concentration of orientation values between $10^{\circ}$ and $18^{\circ}$, with a peak around $14^{\circ}$. This distribution is characteristic of the green group identified manually by historians, however, with higher eastward orientation values.

\section{2. Urban elements}

A similar analysis was carried out on the built-up urban elements surveyed at large scale from the aerial photography of 2006, and the results join those obtained with the cadastral plots.

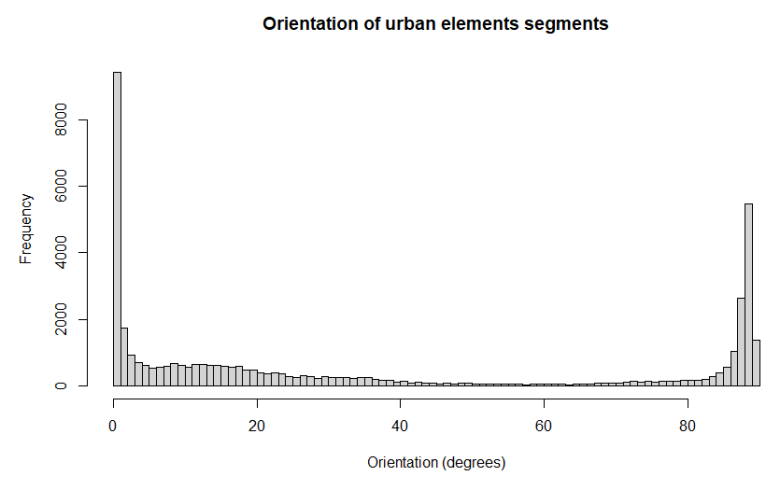

Figure 13. Distribution of the orientations of urban elements (between $0^{\circ}$ et $90^{\circ}$ ) on the entire city of Diyarbakır

In general, the predominant orientations focus on values $0^{\circ}$ and $90^{\circ}$, corresponding to North-South and East-West orientations (figure 13).

By dividing the study area into quadrants, as shown in the figure 14, the analysis of the distribution of orientations is consistent with the observations performed on the cadastral parcels. 


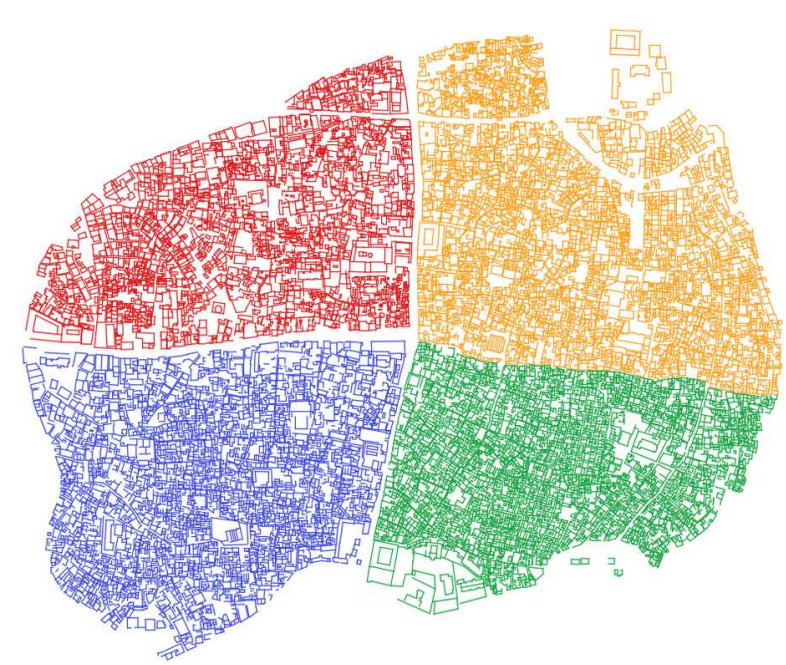

Figure 14. Division of urban elements of the city of Diyarbakır in 4 quadrants

Thus, the North-West, North-East and South-West quadrants are marked by urban built-up elements oriented mainly North-South and East-West. On the other hand, the south-eastern quadrant presents many urban elements with orientation values between $10^{\circ}$ and $30^{\circ}$, with a peak around $17^{\circ}$ (figure 15).

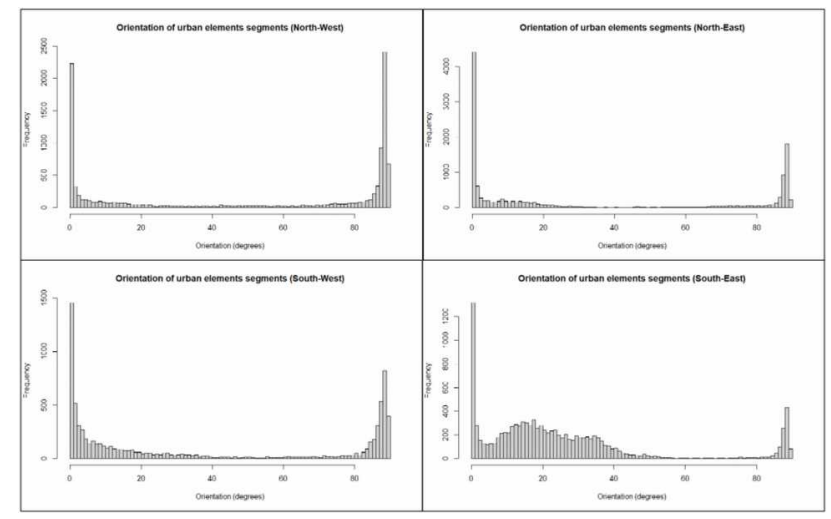

Figure 15. Distribution of the orientations of urban elements (between $0^{\circ}$ et $90^{\circ}$ ) in each quadrants

Although the orientation values are also different from those observed by manual restitution, these values tend to confirm the presence of the green group in the southeastern quadrant of the city, and the existence of an urban structure specific to this part of the historical center of Diyarbakır. However, at the present time, the origin of this structure has not yet been determined.

\section{Discussions}

The various methods to analyze orientations of urban elements of the city of Diyarbakir present consistent results, although significant differences can be observed in terms of orientations values or distribution of main urban structures inherited from the past.
Where human interpretation, by manual capture, took into account the historical deterioration of the alignments (for example, a street which undulates but whose route systematically passes by a fixed axis), the automated application divides the evidences that no visual interpretation will link them together. On the other hand, the result obtained by the automated method reveals a mass of indices much denser than on the manual statement. The digitizing of the aerial photography and of the parcels was indeed carried out on a computer screen from which it was possible to zoom in the image and thus capture as much information as possible with a high level of detail.

For these same reasons, more red elements appear in the eastern part of the city and more green elements appear in the western part of the city. This automated rendering shows a clearer presence of the red structure to the East of the city. The automated survey of orientations also allows us to consider that the green structure may have extended further West than the manual survey suggested.

The groups of traces which seem the most coherent (for example the market of the city center, located at the south of the great mosque, for the red city, or the Gavur Meydanı for the green city) correspond in reality to redeveloped sectors and whose plans have undergone a rectification relatively recent associated with parcels divisions.

The peripheral traces located near the city center walls are too minority in their environment to be able to say that they correspond respectively to a proven extension of the green or red groups. They appear in areas that were very little built at least in the first half of the twentieth century, and do not form a coherent whole. From this point of view, the manual reading seems to be more realistic.

At this stage of the study, it should be noted that in no case the ancient plans have been restored. We relied on the persistence of the orientations, in particular those of the major axes escaping from the gates of the Roman wall, to identify the dominant orientations in the current urban frame, assuming that if the influence on the ground of these axes had necessarily varied since Antiquity, their general directions had been maintained.

Manual or automatic restitution have clearly shown a close association between cardines and decumani and the urban elements that come from the degradation and evolution of old urban plans. The observation of the orientations within the buildings of the Great Mosque points in the same direction. We find in fact the two major orientations identified and whose stabilization cannot be much later than the 13th century, when the 
main buildings making up this architectural ensemble are already in place, as evidenced by a series of inscriptions (Gabriel, 1940: 190-194).

In addition, recent archaeological excavations carried out in the sector of the east wing and the north wing of the mosque, have uncovered ancient and Byzantine structures perpetuated by current buildings oriented like the red structure (Halifeoğlu \& Assénat, 2020).

\section{Conclusion and future works}

This study made it possible to compare two methods, one manual and the other automated, to extract the main orientations in an urban structure, and thus try to reveal the testimonies of the different periods of foundation of the Roman city of Amida.

If the manual restitution of orientations, which depends on the expertise of the historian operator, tends to recompose a coherent structure by retaining indices presenting small deviations of orientation, the automated restitution of orientations does not allow us to take into account the breathing of the urban frames over time. On the other hand, it gives a more objective count than the manual rendering and can show more clearly the extension of the different frames. Thus, the combination of the two approaches has the advantage of giving a statistical and visualisable overview of the representation of inherited orientations and their distribution in space.

In the city of Amida / Diyarbakir it is possible to show that two isoclinic orientations with ancient major axes unequally share the current urban frame. The apparent orthogonality of the urban grid of the historical center of Diyarbakir is an optical illusion made possible by the very slight difference between these two orientations.

This research will now be completed with metrological measurements, in order to confirm if the different frames observed in the current structure of the city of Diyarbakir can be associated with periodic spacings characteristic of particular periods.

\section{References}

Assénat, M. and Pérez, A. (2012). Amida 1. Un théatre antique à Amida. Anatolia Antiqua 20: 147-155.

Assénat, M. and Pérez, A. (2014). Amida 4. Constance II et Amida, Anatolia Antiqua 22 :199-217.

Duchêne, C., Bard, S., Barillot, X., Ruas, A., Trévisan, J. and Holzapfel, F. (2003). Quantitative and qualitative description of building orientation, 6th ICA Workshop on Generalisation and Multiple Representation, 28-30 April, Paris (France).
Gabriel, A. (1940). Voyages archéologiques en Turquie orientale. Paris, de Boccard.

Girres, J.-F., Assenat, M., Ralite, R. and Ribo-Delissey, E. (2018). Spatial Periodicity Analysis of Urban Elements: Application to the Ancient City of Amida. 10th International Conference on Geographic Information Science, 291-296.

Halifeoğlu, F., M. and Assénat, M. (2020). Evaluation of the Excavations Carried Out between 2010 and 2017 in Diyarbakır Grand Mosque Complex for Restoration Work. Hanafis Section and Eastern Maksurah, International Journal of Architectural Heritage, DOI: 10.1080/15583058.2020.1765050;

QGIS.org (2021). QGIS Geographic Information System. QGIS Association. http://www.qgis.org

Rodier, X. (2011). Information spatiale et archéologie. Paris, Errance, 256 p. 